\title{
Vector competence of northern European Culex pipiens biotypes and hybrids for West Nile virus is differentially affected by temperature
}

\author{
Chantal B. F. Vogels ${ }^{1 *}$, Jelke J. Fros ${ }^{2,3}$, Giel P. Göertz ${ }^{2}$, Gorben P. Pijlman ${ }^{2}$ and Constantianus J. M. Koenraadt ${ }^{1}$
}

\begin{abstract}
Background: Outbreaks of West Nile virus (WNV) have not occurred in northern Europe despite nearby circulation of WNV in the southern part of the continent. The main vector for WNV, the mosquito Culex (CX.) pipiens, consists of two behaviorally distinct biotypes, pipiens and molestus, which can form hybrids. Although temperature has been shown to influence vector competence of $C$. pipiens for WNV and biotypes are differentially susceptible towards infection, the interaction between the two has not been elucidated.

Methods: We determined vector competence of the Cx. pipiens biotypes and hybrids, after 14 days of incubation at 18,23 and $28^{\circ} \mathrm{C}$. Mosquitoes were orally infected by providing an infectious blood meal or by injecting WNV directly in the thorax. Infection and transmission rates were determined by testing the bodies and saliva for WNV presence. In addition, titers of mosquitoes with WNV-positive bodies and saliva samples were determined.

Results: Orally infected biotype pipiens and hybrids showed significantly increased transmission rates with higher temperatures, up to 32 and $14 \%$, respectively. In contrast, the molestus biotype had an overall transmission rate of $10 \%$, which did not increase with temperature. All mosquitoes that were infected via WNV injections had (close to) $100 \%$ infection and transmission rates, suggesting an important role of the mosquito midgut barrier. We found no effect of increasing temperature on viral titers.

Conclusions: Temperature differentially affected vector competence of the Cx. pipiens biotypes. This shows the importance of accounting for biotype-by-temperature interactions, which influence the outcomes of vector competence studies. Vector competence studies with $C$. pipiens mosquitoes differentiated to the biotype level are essential for proper WNV risk assessments.
\end{abstract}

Keywords: Arbovirus, Culex, Vector competence, West Nile virus, Infection, Temperature

\section{Background}

West Nile virus (WNV; family Flaviviridae) is the most widespread arthropod-borne virus (arbovirus) in the world and can be fatal for humans [1]. The enzootic cycle of WNV is maintained among mosquitoes and birds, whereas mammals (including humans) are deadend hosts. Outbreaks of WNV have not occurred in northern Europe despite the high abundance of

\footnotetext{
* Correspondence: chantal.vogels@wur.nl

'Laboratory of Entomology, Wageningen University, P.O. Box 16, 6700 AA

Wageningen, The Netherlands

Full list of author information is available at the end of the article
}

competent mosquito vectors $[2,3]$, susceptible bird hosts $[4,5]$, and nearby circulation of WNV in southern Europe [6].

The epidemic potential of WNV is best illustrated by the repeated outbreaks in North America [7]. After the initial introduction of WNV in New York in 1999, WNV rapidly spread across the continent, resulting in the largest outbreak of neuro-invasive disease to date $[8,9]$. American passeriform bird species are the main hosts for WNV, with the family of the corvids (Corvidae) being highly susceptible $[8,10-12]$. Compared to North America, WNV-associated death rates among birds in 
southern Europe have been relatively low. It has, therefore, been hypothesized that European bird species are less susceptible to WNV compared to their North American counterparts. Recent studies confirmed, however, that three important bird species originating from Europe, the carrion crow, European jackdaw, and house sparrow, are highly susceptible to WNV $[4,5,13]$.

Culex pipiens mosquitoes have been identified as the most important vector species for WNV in the United States, because of their vector competence and high abundance during summer [14]. The species Cx. pipiens consists of two morphologically identical biotypes, named $C x$. pipiens pipiens (Linnaeus, 1758) and $C x$. pipiens molestus (Forskål, 1775), which show distinct behavior $[15,16]$. Biotype pipiens prefers birds as blood hosts whereas biotype molestus prefers mammals [15]. As a consequence, biotype pipiens plays an important role in the natural transmission cycle of WNV. Hybrids between the two biotypes have an intermediate host preference, which makes them ideal vectors to bridge WNV from birds to mammals [17]. The presence and abundance of hybrids may, therefore, strongly increase the risk of WNV outbreaks in the human population.

Previous studies showed that proper identification and separation of biotypes is essential, because genetic differences between biotypes and populations influence vector competence [18-20]. Furthermore, our previous studies showed that temperature is an important determinant of vector competence of $C x$. pipiens mosquitoes for WNV $[2,3]$. However, vector competence of the $C x$. pipiens biotypes has not been tested at different temperatures. Transmission of another arbovirus, the chikungunya virus, has been shown to strongly depend on complex interactions between Aedes albopictus populations, viral strains and temperature [21]. The aim of this study was, therefore, to determine the effect of the interaction between temperature and the $C x$. pipiens biotypes on WNV transmission. Vector competence studies with northern European populations of both $C x$. pipiens biotypes and hybrids at different temperatures are necessary, to assess the risks for northern Europe in the light of climate change [22, 23].

\section{Methods}

\section{Mosquitoes}

Culex pipiens egg rafts were collected during June and July 2014 from aboveground water barrels in Best, The Netherlands. One larva from each egg raft was identified to the biotype level with real-time PCR [24]. Culex pipiens colony was started by grouping larvae from 162 egg rafts molecularly identified as biotype pipiens. F3 offspring were used for oral virus infection studies, and F5 offspring for virus infection via intra-thoracic injections. Culex pipiens biotype molestus egg rafts and larvae were collected during September 2013 and February 2014 from an underground habitat in Schiphol airport, Amsterdam, The Netherlands. The colony was started from 38 egg rafts that were autogenously laid by the mosquitoes that emerged from the egg rafts and larvae collected at Schiphol. Real-time PCR confirmed the molestus biotype. Crosses between male biotype pipiens and female biotype molestus resulted in F1 hybrid progeny. The reverse cross between biotypes was not able to produce viable offspring.

All larvae and adults were maintained at $23{ }^{\circ} \mathrm{C}$ with 16:8 light:dark photocycle and $60 \%$ relative humidity. Egg rafts were transferred to trays $(25 \times 25 \times 8 \mathrm{~cm})$ filled with water and a drop of Liquifry No. 1 (Interpet Ltd., Dorking, UK). Thereafter, they were daily fed with a 1:1:1 mixture of bovine liver powder, ground rabbit food and ground koi food. Pupae were transferred to Bugdorm cages $(30 \times 30 \times 30 \mathrm{~cm})$ and provided with $6 \%$ ad libitum glucose solution. Bovine or chicken blood (Kemperkip, Uden, The Netherlands) was provided through a Hemotek $^{\circ}$ PS5 feeder (Discovery Workshops, Accrington, UK) for egg production. Female mosquitoes were kept together with males for 4 to 19 days before being transferred to the Biological Safety Level (BSL) 3 facility. Variation in age was kept similar for the two biotypes and their hybrids. To increase mosquito blood-feeding rates, the glucose solution was replaced by water four to six days before the infectious blood meal was offered.

\section{Virus}

In all experiments a P2 stock of West Nile virus lineage 2 originating from Greece (2010) was used with a $50 \%$ tissue culture infective dose ranging between $7.96 \times 10^{7}$ $\mathrm{TCID}_{50} / \mathrm{ml}$ and $1.12 \times 10^{9} \mathrm{TCID}_{50} / \mathrm{ml}$. WNV was grown on Ae. albopictus $\mathrm{C} 6 / 36$ cells and titrated on Green monkey kidney Vero E6 cells. C6/36 cells were cultured with Leibovitz L15 medium (Life technologies, Bleiswijk, The Netherlands) supplemented with $10 \%$ Fetal Bovine Serum (FBS; Life technologies). Vero E6 cells were cultured with Hepes-buffered DMEM medium (Life technologies) supplemented with $10 \% \mathrm{FBS}$, penicillin (100 IU/ml; Sigma-Aldrich, Zwijndrecht, The Netherlands) and streptomycin $(100 \mu \mathrm{g} / \mathrm{ml}$; SigmaAldrich). The medium was fully supplemented by adding Fungizone $(2.5 \mu \mathrm{g} / \mathrm{ml}$; Life technologies $)$ and gentamycin (50 $\mu \mathrm{g} / \mathrm{ml}$; Life technologies) when viral infection or titers were determined from mosquito homogenates.

\section{WNV infection}

To determine the period until peak transmission rates and viral titers have developed, we determined viral titers up to 35 days post-infection. Biotype pipiens mosquitoes were injected with $69 \mathrm{nl}$ of WNV $\left(1.12 \times 10^{9}\right.$ $\mathrm{TCID}_{50} / \mathrm{ml}$ ) using the Drummond Nanoject II Auto- 
Nanoliter Injector (Drummond Scientific Company, Broomall, PA, United States). Capillaries (3.5" Drummond \# 3-000-203-G/X, Drummond Scientific Company) were drawn to a fine point with the Narishige needle puller model PB-7 (Narishige, Tokyo, Japan). Injections instead of infectious blood meals were used in order to obtain $100 \%$ infection [2]. Injected mosquitoes were divided over 6 groups of 24 female mosquitoes, and placed in buckets $(\varnothing: 12.5 \mathrm{~cm}$, height: $12.5 \mathrm{~cm})$ at $23{ }^{\circ} \mathrm{C}$ for $7,14,21,28$ or 35 days. One group of female mosquitoes was directly killed (day 0 ) and individually stored at $-80^{\circ} \mathrm{C}$.

The $C x$. pipiens biotypes and hybrids were orally infected with WNV in order to test for the effect of temperature on infection and transmission rates [2]. In the BSL3 facility, biotype pipiens, biotype molestus, and hybrid mosquitoes were kept in groups of 20-100 females in buckets. Female mosquitoes were allowed to feed for one hour on infectious chicken blood with a titer of $5.7 \pm 1.0 \times 10^{7} \quad \mathrm{TCID}_{50} / \mathrm{ml}$, offered through a Hemotek PS5 feeder. The blood meal was offered during the early stage of the dark period in a dark room at $24^{\circ}$ $\mathrm{C}$ and $60 \% \mathrm{RH}$. After one hour, mosquitoes were immobilized on a semi-permeable $\mathrm{CO}_{2}$-pad connected to $100 \% \mathrm{CO}_{2}$. Blood-fed mosquitoes of each group were selected and divided in smaller groups of maximum 20 female mosquitoes over three separate buckets. The buckets were placed at 18,23 or $28^{\circ} \mathrm{C}$ for 14 days. Oral infections were replicated four to seven times until a total number of 50 female mosquitoes of each biotype per temperature was reached.

To determine the effect of the midgut on WNV dissemination, mosquitoes were also injected with WNV. Biotype pipiens, biotype molestus, and hybrid mosquitoes were immobilized with $\mathrm{CO}_{2}$, and injected in the thorax with $69 \mathrm{nl}$ of WNV $\left(1.12 \times 10^{9} \mathrm{TCID}_{50} / \mathrm{ml}\right)$. Mosquitoes from each group were divided in groups of maximally 12 female mosquitoes over three separate buckets and placed at 18,23 or $28{ }^{\circ} \mathrm{C}$ for 14 days. Injections were replicated three times until a total number of $20 \pm 1$ female mosquitoes of each biotype per temperature was reached.

\section{Infection and transmission rates}

After the incubation period of 14 days, mosquitoes were immobilized with $\mathrm{CO}_{2}$ and legs and wings were removed. To collect saliva, the proboscis of each mosquito was inserted in a pipette tip with $5 \mu$ of a 1:1 solution of FBS and $50 \%$ glucose solution, for a minimum period of $45 \mathrm{~min}$. Each saliva sample was collected in a $1.5 \mathrm{ml}$ Eppendorf safe-lock microcentrifuge tube with $55 \mu \mathrm{l}$ of fully supplemented Hepes-buffered DMEM medium, whereas bodies were individually stored in $1.5 \mathrm{ml}$ Eppendorf safe-lock microcentrifuge tubes with a small scoop of $0.5 \mathrm{~mm}$ Zirconium beads (Bio-Connect BV, Huissen, The Netherlands). All samples were stored at $-80{ }^{\circ} \mathrm{C}$ until further use.

Frozen mosquito bodies were homogenized in the Bullet blender storm (Next Advance, New York, United States) for $2 \mathrm{~min}$, and shortly spun down at 14,000 rpm. Next, $100 \mu \mathrm{l}$ of fully supplemented Hepes-buffered DMEM medium was added and samples were again homogenized for $2 \mathrm{~min}$ in the Bullet blender, and spun down for 2 min at 14,000 rpm. For each mosquito homogenate or saliva sample, $30 \mu \mathrm{l}$ was incubated on a monolayer of Vero E6 cells in a 96-well plate. After $2-3 \mathrm{~h}$ the medium was completely removed and replaced by $100 \mu \mathrm{l}$ of new medium. After three days, each well was scored for cytopathic effects specific for WNV. Titers were determined by endpoint dilution assays on Vero E6 cells, and scored for cytopathic effects after 3 days.

\section{Statistical analysis}

Generalized linear models with a binomial distribution and logit link function were used to test for the effects of biotype and temperature on the WNV infection and transmission rates, for the orally infected mosquitoes. Mosquitoes with positive saliva, but negative body (1\%) were excluded from the analysis. Infection and transmission rates were calculated, respectively, by dividing the number of female mosquitoes with infected bodies or with infected saliva by the total number of female mosquitoes in the respective treatment. Effects of replicate, biotype, temperature, and the interaction term between biotype and temperature, were included in both models. When interaction terms were significant, the effect of temperature was tested separately for each biotype with likelihood ratio (LR) tests. Multiple comparisons were corrected with the Bonferroni procedure, by lowering the significance level from 0.05 to 0.017 . The effect of temperature on viral titers was tested separately for each biotype with Wilcoxon or Kruskal-Wallis tests. All statistical analyses were done with SAS software, version 9.3 (SAS Institute Inc., Cary, USA), and figures were created with the statistical software package $R$ ( $R$ foundation for Statistical Computing, Vienna, Austria).

\section{Results}

To determine the minimum incubation period until peak viral titers were reached, viral titers were assessed for Cx. pipiens biotype pipiens females up to 35 days postWNV infection (Additional file 1: Table S1). Infection rates were $100 \%$ at all time points from day zero to 35 post-infection (Fig. 1a). In addition, at all time points all mosquitoes tested had virus-positive saliva except for one female at day 21 (Fig. 1a). After 14 days, viral titers of the mosquito bodies were approximately 1,000-fold 

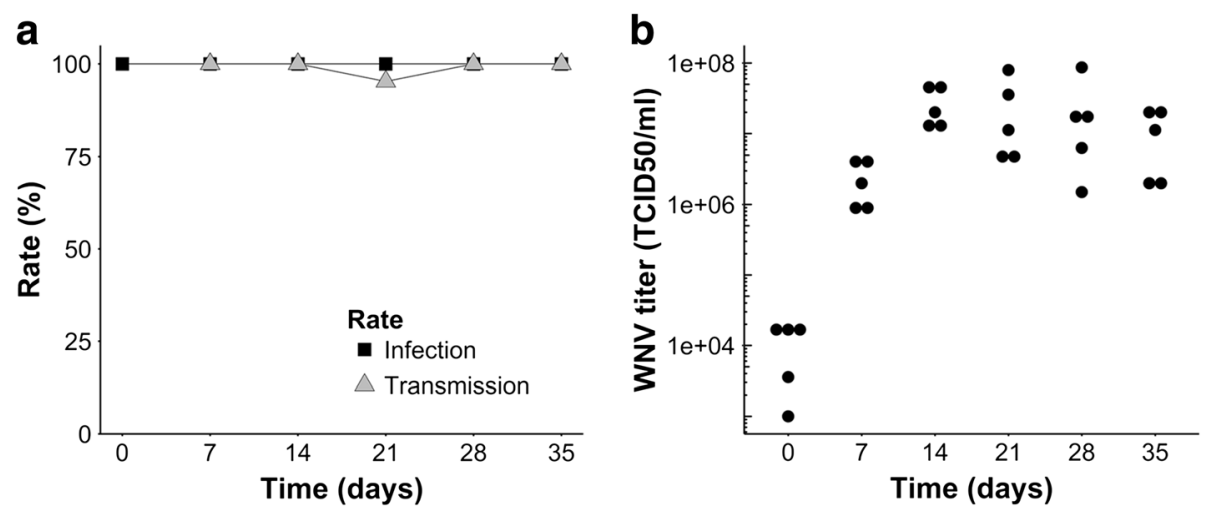

Fig. 1 Vector competence and titers of WNV injected CX. pipiens biotype pipiens females over 35 days. Infection (squares) and transmission (triangles) rates of biotype pipiens females incubated at $23{ }^{\circ} \mathrm{C}$ from day 0 to 35 post-injection (a). Each data point represents $16-24$ mosquitoes. WNV titers of five selected female mosquitoes at each time point from day 0 to 35 post-infection (b)

higher than titers at the day of infection, and remained high over time (average titer of $2 \times 10^{7} \quad \mathrm{TCID}_{50} / \mathrm{ml}$; Fig. 1b).

Infection and transmission rates were determined for orally infected biotype pipiens, biotype molestus, and hybrid females after 14 days of incubation at 18,23 or $28^{\circ}$ C (Additional file 1: Table S2). Initial model analyses of infection rates showed a significant interaction effect between biotype and temperature (GLM, $\chi^{2}=12.89, d f=4$, $P=0.012)$, which indicated that infection rates of biotypes responded differently to temperature (Fig. 2a). Selections were, therefore, made to test for the effect of temperature separately for each biotype. Infection rates were significantly different between temperatures for biotype pipiens (28.6-63.3\%; Likelihood ratio test (LR), $\left.\chi^{2}=12.54, d f=2, P=0.002\right)$, but there was no significant difference for biotype molestus (24.5-14.0\%; LR, $X^{2}=$ 3.96, $d f=2, P=0.14)$, and hybrids (24.0-42.9\%; LR, $\chi^{2}=$ $5.07, d f=2, P=0.080)$. For biotype pipiens, the infection rate was significantly higher at $28{ }^{\circ} \mathrm{C}$ compared to $18{ }^{\circ} \mathrm{C}$
(LR, $\chi^{2}=12.31, d f=1, P<0.001$ ), but not at $23^{\circ} \mathrm{C}$ compared to $18{ }^{\circ} \mathrm{C}$ (LR, $\chi^{2}=4.91, d f=1, P=0.027$; threshold $P$-value $=0.017$ after Bonferroni correction), and 23 compared to $28{ }^{\circ} \mathrm{C}$ (LR, $\chi^{2}=1.79, d f=1, P=0.18$ ). Thus, infection rates of biotype pipiens increased with higher temperatures, with the strongest increase at $28{ }^{\circ} \mathrm{C}$, whereas there was no effect of temperature on infection rates of biotype molestus and hybrids.

To determine whether a female mosquito can actually transmit WNV, transmission rates were determined based on the presence of WNV in the saliva. Model analyses again showed a significant interaction effect between biotype and temperature (GLM, $\chi^{2}=15.71, d f=4$, $P=0.003)$, which indicated that also transmission rates of the biotypes responded differentially to temperature (Fig. 2b). Therefore, the effect of temperature on the transmission rate of each biotype was tested separately. Transmission rates significantly increased with temperature for biotype pipiens $\left(0-32.7 \%\right.$; LR, $X^{2}=29.95, d f=2, P<$ $0.001)$ and hybrids $\left(0-14.3 \%\right.$; LR, $\chi^{2}=13.49, d f=2, P=$
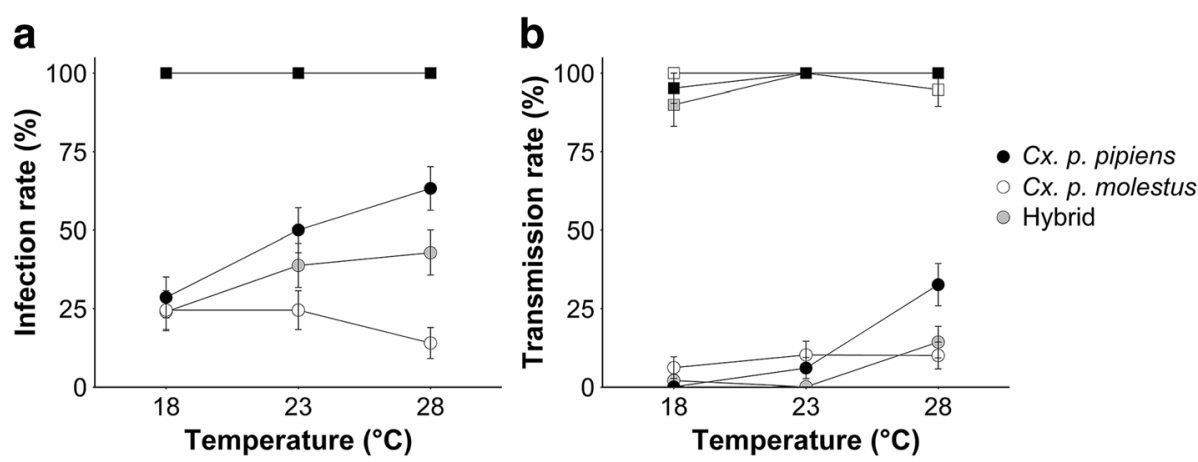

Fig. 2 Vector competence of the $C$. pipiens biotypes and hybrids incubated at 18,23 , or $28^{\circ} \mathrm{C}$ for 14 days. Infection rates (a) and transmission rates (b) of biotype pipiens (black), biotype molestus (white), and hybrids (grey) after oral infection (circles) and injections (squares). Data points of the biotypes and hybrids after injections are overlapping. Each data point represents 50 female mosquitoes for oral infections, and 19-21 female mosquitoes for injections. Error bars show standard error of the means 
0.001), but not for biotype molestus (6.1-10.2 \%; LR, $\chi^{2}=$ $0.77, d f=2, P=0.68)$. For biotype pipiens, the transmission rate was significantly higher at $28{ }^{\circ} \mathrm{C}$ compared to $18{ }^{\circ} \mathrm{C}$ (LR, $\left.\chi^{2}=26.41, d f=1, P<0.001\right)$ and compared to $23{ }^{\circ} \mathrm{C}$ (LR, $\chi^{2}=12.75, d f=1, P<0.001$ ), but not at $23{ }^{\circ} \mathrm{C}$ compared to $18{ }^{\circ} \mathrm{C}$ (LR, $\chi^{2}=4.29, d f=1, P=0.038$; threshold $P$-value $=0.017$ after Bonferroni correction). Also for hybrids, the transmission rate was significantly higher at $28^{\circ}$ C compared to $18^{\circ} \mathrm{C}\left(\mathrm{LR}, \chi^{2}=6.58, d f=1, P=0.010\right)$ and compared to $23{ }^{\circ} \mathrm{C}$ (LR, $\left.\chi^{2}=11.18, d f=1, P<0.001\right)$, but there was no difference between rates at 18 and $23^{\circ} \mathrm{C}$ (LR, $\left.X^{2}=1.35, d f=1, P=0.24\right)$. Thus, transmission rates of biotypes responded differently to temperature, with biotype pipiens and hybrids showing a significant increase with higher temperature, whereas there was no effect of temperature on biotype molestus.

In order to test whether different responses of biotypes to temperature could be attributed to the midgut barrier or the salivary gland barrier, the $C x$. pipiens biotypes and hybrids were injected with WNV. By injecting WNV directly in the thorax the midgut barrier is bypassed and only the salivary gland barrier needs to be overcome before WNV can be transmitted. After 14 days of incubation, the infection rates were $100 \%$ for both biotypes and hybrids, at all temperatures (Fig. 2a). Transmission rates of female mosquitoes at most temperatures were (close to) $100 \%$ (Fig. 2b), suggesting that there is no apparent salivary gland barrier.

Finally, viral titers of all orally infected female mosquitoes with virus-positive body and saliva were determined. The effect of temperature on viral titer was again tested separately for each biotype. There was no significant effect of temperature on median viral titers of biotype pipiens (Wilcoxon test, $Z=1.51, d f=1, P=0.13$; Fig. 3a), biotype molestus (Kruskal-Wallis test, $\chi^{2}=1.96$, $d f=2, P=0.38$; Fig. 3b), and hybrids (Wilcoxon test, $Z=$
1.40, $d f=1, P=0.13$; Fig. $3 \mathrm{c})$. These results demonstrate that viral titers did not increase with higher temperatures, indicating that after successfully passing the midgut barrier there is no difference between the biotypes.

\section{Discussion}

The aim of this study was to investigate the interaction between temperature and $C x$. pipiens biotypes on WNV transmission. We found that temperature differentially affected vector competence of the $C x$. pipiens biotypes and their hybrids. Transmission rates of biotype pipiens $(0-32 \%)$ and hybrids $(0-14 \%)$ increased with higher temperature, especially at $28{ }^{\circ} \mathrm{C}$, whereas transmission rates of biotype molestus (6-10\%) were not affected by temperature. Transmission rates of biotype pipiens were within the range of other $C x$. pipiens populations in WNV endemic areas [25-27]. Peak transmission rates of biotype molestus and hybrids were, however, two- to three-fold lower.

Positive relations between temperature and vector competence are not limited to WNV and Cx. pipiens [2, 27], but have also been described for other virusvector systems $[3,21]$. This positive relation is most likely the result of increased replication of the virus at higher temperatures $[3,28,29]$. Interestingly, the transmission rates of biotype molestus did not increase with higher temperature. In this study, all female mosquitoes were reared under the same controlled conditions. Observed differences between biotypes are, therefore, likely due to interactions between genotype and temperature. When bypassing the midgut barrier by injecting WNV in female mosquitoes, transmission rates were similar for the biotypes and their hybrids. This suggests that genetic factors determining midgut characteristics can explain why temperature had no effect on transmission rates of biotype molestus. The highest temperature may have induced
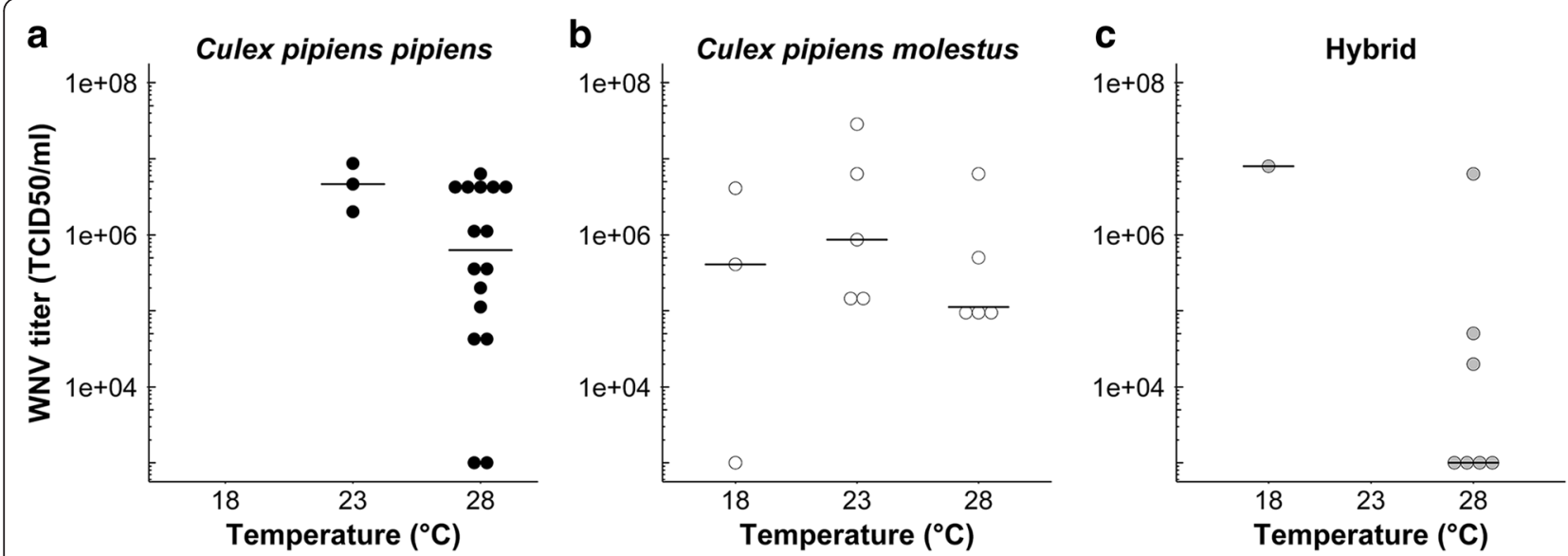

Fig. 3 WNV titers of orally infected CX. pipiens females with virus-positive bodies and saliva. WNV titers were determined after 14 days of incubation at 18,23 , or $28^{\circ} \mathrm{C}$ for biotype pipiens (a), biotype molestus (b) and hybrids (c). Horizontal black lines show median titers at each temperature 
changes in the morphology and physiology of the midgut of biotype pipiens and hybrids. As a result, the effectiveness of the midgut as a barrier may have decreased, whereas there seemed to be a higher threshold for biotype molestus. Such lowered effectiveness of the midgut barrier at higher temperatures has been shown with Ae. albopictus mosquitoes infected with dengue virus [30]. Alternatively, temperature may have induced changes in the regulation of biotype-specific immunoresponsive genes, as has been shown for Aedes aegypti mosquitoes infected with Chikungunya virus [31]. In addition, the RNAi pathway becomes more active at higher temperatures and can inhibit viral replication [32]. Differences in RNAi activity between the biotypes may have resulted in increased sensitivity for WNV infection of biotype pipiens and hybrids at higher temperatures, whereas such changes were not induced in biotype molestus. Future studies should focus on the underlying mechanisms in the midgut that can explain why vector competence of biotype molestus for WNV did not increase with higher temperature.

Vector competence of Cx. pipiens for WNV varies in time and among different mosquito populations [33]. Vector competence of North American lines of biotype pipiens (Pennsylvania) and of biotype molestus (New Jersey) populations were equal, but lower than vector competence of their hybrid progeny [19]. In contrast, significant differences in vector competence were found between biotype pipiens (Woodland) and biotype molestus (Sacramento) populations [20]. No differences in transmission rates were found between four different autogenous and anautogenous $C x$. pipiens populations in Italy [26]. Our study shows that such variation can be partly explained by temperature, but other complex interactions between viral strains, viral titers, and geographically distinct vector populations have been shown to play a role as well $[2,21,34]$. In addition, colonization in the laboratory could have influenced the outcomes of these vector competence studies [35-38]. Such effects have been shown to occur after eight generations for $C x$. pipiens mosquitoes infected with Rift Valley Fever virus [35], but this is dependent on the number of females the colony was established with, and selection pressures in the rearing environment [36, 37]. In order to fully understand factors that are required for WNV transmission, a direct comparison should be made between vector competence of recently established mosquito populations originating from endemic and non-endemic areas at different temperatures.

Vector competence is only one qualitative component of the more complex, quantitative vectorial capacity of a species to transmit pathogens $[39,40]$. Vectorial capacity also takes into account other factors such as vector and host abundance, host preference, biting rate and survival. Our results confirm that temperature is an important factor that may explain the current absence of WNV transmission in northern Europe. Temperature is, however, not the only factor that can predict when and where WNV transmission cycles can be established [41]. In order to determine the risk of WNV establishment and further transmission, it is essential to use valid predictors of all components of vectorial capacity in risk models. Our results emphasize the need to characterize $C x$. pipiens populations to the biotype level for reliable assessments of the risk for future WNV outbreaks.

Based on our findings that there is an increased likelihood of WNV transmission by $C x$. pipiens at higher temperatures, and climate change predictions of longer and more intense heat waves during summer [22, 23], future WNV transmission in northern Europe cannot be ruled out. Preparing for future WNV transmission in northern Europe is, therefore, advised.

\section{Conclusion}

Vector competence of the Cx. pipiens biotypes and their hybrids for WNV is differentially affected by temperature. Transmission rates of biotype pipiens and hybrids increased with higher temperatures, but not so for biotype molestus. Our study emphasizes the need to identify $C x$. pipiens mosquitoes to the biotype level because of the differential vector competence and vectorial capacity for WNV.

\section{Additional file}

Additional file 1: Table S1. Supporting data for experiment on incubation period until peak WNV titers. Table S2. Supporting data for experiment on vector competence of $C X$. pipiens biotypes for WNV. (XLSX $73 \mathrm{~kb})$

\section{Abbreviations}

Arbovirus, arthropod-borne virus; BSL, biological safety level; FBS, fetal bovine serum; GLM, generalized linear model; LR, likelihood ratio test; $\mathrm{TCID}_{50}, 50 \%$ tissue culture infective dose; WNV, West Nile virus

\section{Acknowledgements}

We thank Wietse den Hartog for collecting biotype molestus from the field, Corinne Geertsema for maintenance of cell cultures, Gerrit Gort for support with statistical analyses, and Marcel Dicke for providing comments on an earlier version of this manuscript.

\section{Funding}

This work was supported by the European Community's Seventh Framework Programme [FP7 VECTORIE project number 261466].

Availability of data and materials

All relevant data are within the paper and its supporting information files.

Authors' contributions

CBFV, JJF, GPP and CJMK designed the study; CBFV and GPG performed experiments; CBFV analyzed data; CBFV wrote the manuscript; JJF, GPG, GPP and CJMK contributed to writing of the manuscript. All authors read and approved the final version of the manuscript.

Competing interests

The authors declare that they have no competing interests. 


\section{Consent for publication}

Not applicable.

\section{Ethics approval and consent to participate}

Not applicable.

\section{Author details}

'Laboratory of Entomology, Wageningen University, P.O. Box 16, 6700 AA Wageningen, The Netherlands. ${ }^{2}$ Laboratory of Virology, Wageningen University, P.O. Box 16, 6700 AA Wageningen, The Netherlands. ${ }^{3}$ Nuffield Department of Medicine, Peter Medawar Building for Pathogen Research, University of Oxford, Oxford OX1 3SY, England, UK.

\section{Received: 10 May 2016 Accepted: 30 June 2016}

\section{Published online: 07 July 2016}

\section{References}

1. Kramer LD, Styer LM, Ebel GD. A global perspective on the epidemiology of West Nile virus. Annu Rev Entomol. 2008:53:61-81.

2. Fros JJ, Geertsema C, Vogels CB, Roosjen PP, Failloux AB, Vlak JM, et al. West Nile virus: High transmission rate in north-western European mosquitoes indicates its epidemic potential and warrants increased surveillance. PLoS Negl Trop Dis. 2015;9(7), e0003956.

3. Fros JJ, Miesen P, Vogels CB, Gaibani P, Sambri V, Martina BE, et al. Comparative Usutu and West Nile virus transmission potential by local Culex pipiens mosquitoes in north-western Europe. One Health. 2015;1:31-6.

4. Lim SM, Brault AC, van Amerongen G, Bosco-Lauth AM, Romo H, Sewbalaksing VD, et al. Susceptibility of carrion crows to experimental infection with lineage 1 and 2 West Nile Viruses. Emerg Infect Diseases. 2015;21(8):1357.

5. Lim SM, Brault AC, van Amerongen G, Sewbalaksing VD, Osterhaus ADME, Martina BEE, Koraka P. Susceptibility of European jackdaws (Corvus monedula) to experimental infection with lineage 1 and 2 West Nile viruses. J Gen Virol. 2014;95(6):1320-9.

6. Hubalek Z, Halouzka J. West Nile fever - a reemerging mosquito-borne viral disease in Europe. Emerg Infect Diseases. 1999;5(5):643-50.

7. Hayes EB, Komar N, Nasci RS, Montgomery SP, O'Leary DR, Campbell GL. Epidemiology and transmission dynamics of West Nile virus disease. Emerg Infect Diseases. 2005;11(8):1167-73.

8. Hayes $E B$, Gubler DJ. West Nile virus: epidemiology and clinical features of an emerging epidemic in the United States. Annu Rev Med. 2006;57(1):181-94.

9. Lanciotti RS, Roehrig JT, Deubel V, Smith J, Parker M, Steele K, et al. Origin of the West Nile Virus responsible for an outbreak of encephalitis in the northeastern United States. Science. 1999;286(5448):2333-7.

10. Komar N, Langevin S, Hinten S, Nemeth N, Edwards E, Hettler D, et al. Experimental infection of North American birds with the New York 1999 strain of West Nile virus. Emerg Infect Diseases. 2003:9(3):311.

11. Wheeler SS, Barker CM, Fang Y, Veronica Armijos M, Carroll BD, et al. Differential impact of West Nile Virus on California birds. Condor. 2009:111(1):1-20.

12. Work TH, Hurlbut HS, Taylor RM. Indigenous wild birds of the Nile delta as potential West Nile virus circulating reservoirs. Am J Trop Med Hyg. 1955; 4(5):872-88.

13. Del Amo J, Llorente F, Pérez-Ramirez E, Soriquer RC, Figuerola J, Nowotny N, Jiménez-Clavero MA. Experimental infection of house sparrows (Passer domesticus) with West Nile virus strains of lineages 1 and 2. Vet Microbiol. 2014:172(3-4):542-7.

14. Kilpatrick AM, Kramer LD, Campbell SR, Alleyne EO, Dobson AP, Daszak P. West Nile virus risk assessment and the bridge vector paradigm. Emerg Infect Diseases. 2005;1 1(3):425-9.

15. Byrne K, Nichols RA. Culex pipiens in London Underground tunnels: differentiation between surface and subterranean populations. Heredity. 1999:82(1):7-15.

16. Vinogradova EB. Culex pipiens pipiens mosquitoes: taxonomy, distribution, ecology, physiology, genetic, applied importance and control. Sofia: Pensoft Publishers; 2000

17. Fritz ML, Walker ED, Miller JR, Severson DW, Dworkin I. Divergent host preferences of above- and below-ground Culex pipiens mosquitoes and their hybrid offspring. Medical and Vet Entomol. 2015;29(2):115-23.

18. Brustolin M, Talavera S, Santamaría C, Rivas R, Pujol N, Aranda C, et al. Culex pipiens and Stegomyia albopicta (= Aedes albopictus) populations as vectors for lineage 1 and 2 West Nile virus in Europe. Medical and Vet Entomol. 2016; 30(2):166-173.
19. Ciota AT, Chin PA, Kramer LD. The effect of hybridization of Culex pipiens complex mosquitoes on transmission of West Nile virus. Parasit Vectors. 2013;6(1):305

20. Nelms BM, Kothera L, Thiemann T, Macedo PA, Savage HM, Reisen WK. Phenotypic variation among Culex pipiens complex (Diptera: Culicidae) populations from the Sacramento Valley, California: Horizontal and vertical transmission of West Nile virus, diapause potential, autogeny, and host selection. Am J Trop Med Hyg. 2013;89(6):1168-78.

21. Zouache K, Fontaine A, Vega-Rua A, Mousson L, Thiberge J-M, Lourenco-DeOliveira $R$, et al. Three-way interactions between mosquito population, viral strain and temperature underlying chikungunya virus transmission potential. Proc R Soc Lond B. 2014;281(1792).

22. Beniston M, Stephenson DB, Christensen OB, Ferro CAT, Frei C, Goyette $\mathrm{S}$, et al. Future extreme events in European climate: an exploration of regional climate model projections. Clim Chang. 2007;81(1):71-95.

23. Meehl GA, Tebaldi C. More intense, more frequent, and longer lasting heat waves in the 21st century. Science. 2004;305(5686):994-7.

24. Vogels CBF, Van De Peppel LJJ, Van Vliet AJH, Westenberg M, Ibañez-Justicia A, Stroo A, et al. Winter activity and aboveground hybridization between the two biotypes of the West Nile virus vector Culex pipiens. Vector Borne Zoonotic Dis. 2015;15(10):619-26.

25. Balenghien $T$, Vazeille $M$, Grandadam $M$, Schaffner F, Zeller $H$, Reiter $P$, et al. Vector competence of some French Culex and Aedes mosquitoes for West Nile virus. Vector Borne Zoonotic Dis. 2008;8(5):589-95.

26. Fortuna C, Remoli ME, Di Luca M, Severini F, Toma L, Benedetti E, et al. Experimental studies on comparison of the vector competence of four Italian Culex pipiens populations for West Nile virus. Parasit Vectors. 2015;8(1):1-10.

27. Kilpatrick AM, Meola MA, Moudy RM, Kramer LD. Temperature, viral genetics, and the transmission of West Nile virus by Culex pipiens mosquitoes. PLoS Pathog. 2008:4(6), e1000092.

28. Chamberlain RW, Sudia WD. Mechanism of transmission of viruses by mosquitoes. Annu Rev Entomol. 1961;6(1):371-90.

29. Hardy JL, Houk EJ, Kramer LD, Reeves WC. Intrinsic factors affecting vector competence of mosquitoes for arboviruses. Annu Rev Entomol. 1983;28: 229-62.

30. Alto BW, Bettinardi D. Temperature and Dengue virus infection in mosquitoes: independent effects on the immature and adult stages. Am J Trop Med Hygiene. 2013;88(3):497-505.

31. Mourya DT, Yadav P, Mishra AC. Effect of temperature stress on immature stages and susceptibility of Aedes aegypti mosquitoes to Chikungunya virus. Am J Trop Med Hygiene. 2004;70(4):346-50.

32. Adelman ZN, Anderson MAE, Wiley MR, Murreddu MG, Samuel GH, Morazzani EM, Myles KM. Cooler temperatures destabilize RNA interference and increase susceptibility of disease vector mosquitoes to viral infection. PLoS Negl Trop Diseases. 2013;7(5), e2239.

33. Vaidyanathan R, Scott TW. Geographic variation in vector competence for West Nile virus in the Culex pipiens (Diptera: Culicidae) complex in California. Vector Borne Zoonotic Dis. 2007:7(2):193-8.

34. Anderson SL, Richards SL, Tabachnick WJ, Smartt CT. Effects of West Nile virus dose and extrinsic incubation temperature on temporal progression of vector competence in Culex pipiens quinquefasciatus. J Am Mosq Control Assoc. 2010:26(1):103-7.

35. Gargan TP, Bailey CL, Higbee GA, Gad A, El Said S. The effect of laboratory colonization on the vector-pathogen interactions of Egyptian Culex pipiens and Rift Valley Fever Virus. Am J Trop Med Hyg. 1983;32(5):1154-63.

36. Grimstad PR, Craig Jr GB, Ross QE, Yuill TM. Aedes triseriatus and La Crosse virus: geographic variation in vector susceptibility and ability to transmit. Am J Trop Med Hyg. 1977;26(5):990-6.

37. Jones RH, Foster NM. Relevance of laboratory colonies of the vector in arbovirus research - Culicoides variipennis and Bluetongue. Am J Trop Med Hyg. 1978;27(1):168-77.

38. Lorenz L, Beaty BJ, Aitken THG, Wallis GP, Tabachnick WJ. The effect of colonization upon Aedes aegypti susceptibility to oral infection with Yellow Fever virus. Am J Trop Med Hyg. 1984;33(4):690-4.

39. Garrett-Jones C. The human blood index of malaria vectors in relation to epidemiological assessment. Bull World Health Organ. 1964;30(2):241-61.

40. Garrett-Jones C. Prognosis for interruption of malaria transmission through assessment of the mosquito's vectorial capacity. Nature. 1964;204:1173-5.

41. Marcantonio M, Rizzoli A, Metz M, Rosà R, Marini G, Chadwick E, Neteler M. Identifying the environmental conditions favouring West Nile virus outbreaks in Europe. PLoS One. 2015;10(3):e0121158. 